\title{
The effects of litter size on emotional reactivity in BALB/c mice*
}

\author{
RICHARD C. LaBARBA, JERRY L. WHITE, \\ ALLEN STEWART, and NANCY BUCKLEY \\ University of South Florida, Tampa, Fla. 33620
}

The relationship between litter size and emotional reactivity in $\mathrm{BALB} / \mathrm{c}$ mice was investigated. Emotional reactivity was measured by obtaining data on activity level, quadrants traversed, and defecation in an automated open field for 3 consecutive days, beginning at 60 days of age. Groups of mice were reared in litter sizes of nine, three, and one. On the measures of activity level and quadrants traversed, mice reared in large litters displayed more emotional reactivity than those reared in small litters. The problem of defecation as a reliable index of emotional reactivity was discussed.

In a recent study (LaBarba \& White, 1971), it was found that litter size variations of nine pups and three pups resulted in differential adult emotional reactivity in BALB/c mice. Mice reared in large litters displayed significantly higher levels of emotional reactivity than did those reared within smaller litters. These effects were found to be consistent across three behavioral indices of emotionality obtained in an open field: general activity, quadrants traversed, and defecation. Insofar as the data in this area of investigation have been inconsistent (LaBarba \& White, 1971), the purpose of this study was to obtain additional information on this phenomenon by replicating and extending the earlier findings of the authors.

\section{METHOD}

Thirty-three litters of BALB/c mice containing nine or more pups were chosen randomly from a large number of available litters. Four of these litters were culled to nine pups each and comprised a large litter group of Ss. Another 12 litters were culled to three pups each to establish an intermediate-sized group. The remaining 17 litters were reduced to litters of one pup each and were designated as a small litter group. Only litters of nine or more pups were used to establish the three groups in order to control for any biological factors attending the occurrence of naturally large vs naturally small litters in either the mothers or the offspring. All females were nulliparous prior to breeding. The total number of Ss used was 89: 36 mice in each of the large and intermediate groups, and 17 in the small litter group. The large litter group contained 20 males and 16 females, the intermediate group 17 males and 19 females, and the small litter group 10 males and 7 females.

All animals were raised under standard laboratory conditions and in standard plastic mouse cages, with Iso-Dri compressed wood chips for bedding material. All animals were weaned and housed individually in cages at 21 days of age and placed on an ad lib food and water schedule. The mice were never handled thereafter until testing began. At 60 days of age, the Ss were

*This research was partially funded by a release time grant award from the Office of Sponsored Research at the University of South Florida. Requests for reprints should be sent to the senior author, Department of Psychology, University of South Florida, Tampa, Florida 33620 . This paper is sponsored by David E. Clement, who takes responsibility for its contents. tested in an automated open field for 3 consecutive days. Three dependent measures of emotional reactivity were obtained: general activity level, quadrants traversed, and defecation. The open-field apparatus was a Lehigh Valley automated quadrant activity cage (Model 1497).

This apparatus provides for a precise and objective record of activity. Each animal was placed in the activity cage for $3 \mathrm{~min}$ on each of the 3 consecutive test days. The floor and walls of the cage were wiped with a diluted vinegar solution after each animal completed its 3-min trial to remove any odors.

\section{RESULTS}

The data were analyzed by a mixed-design analysis of variance. An unweighted means solution was used because of unequal and disproportionate cell frequencies.

The ANOVA for activity level showed a significant litter size effect $(\mathrm{F}=17.45, \mathrm{df}=2 / 83, \mathrm{p}<.001)$ and a significant days effect $(F=3.61, d f=2 / 166, p<.05)$. No sex differences or interaction effects were found for activity level. The mean activity level of small litters (309.2) was significantly higher $(p<.001)$ than that of large litters (177.4). The mean level of activity for intermediate-sized litters (258.7) was also significantly higher $(p<.001)$ than for large litters. Although the small litter group was more active than the intermediate-size group, this difference was not significant. The significant days effect is accounted for by a decrease in mean activity level from Day 1 of testing to Day 3. Student's $t$ tests indicate that the Day 1 mean for activity (249.1) is not significantly different from Day 2 (242.4) but that the activity level on Day 3 of testing (214.9) is significantly different from both Days 1 and $2(\mathrm{p}<.001)$.

For the dependent measure of quadrants traversed, the litter size effect was also significant $(F=21.1$, $\mathrm{df}=2 / 83, \mathrm{p}<.001)$. The mean number of quadrants traversed for large, intermediate, and small litters were $13.3,24.0$, and 35.2 , respectively. These means are all significantly different from each other $(p<.01)$. All other effects and interactions on the measure of quadrants traversed were nonsignificant.

The ANOVA on defecation rates yielded a significant litter size effect $(F=4.86, d f=2 / 83, p<.025)$ and a significant days effect $(F=4.53, \mathrm{df}=2 / 166, \mathrm{p}<.025)$. For large litters, the mean defecation was 3.44 , for intermediate litters, 2.15 , and for small litters, 4.25 . The only significant difference obtained between these means was that between the intermediate and small litter rates of defecation $(p<.05)$. The significant days effect on the defecation variable is revealed by the increase in mean defecation from Day 1 (2.57) to Day 2 (2.94) to Day 3 (3.70). Here Day 3 is significantly different from Days 1 and $2(p<.01)$. Days 1 and 2 are not significantly different from each other. No significant 
sex or interaction effects were found for defecation.

The data are summarized in Table 1.

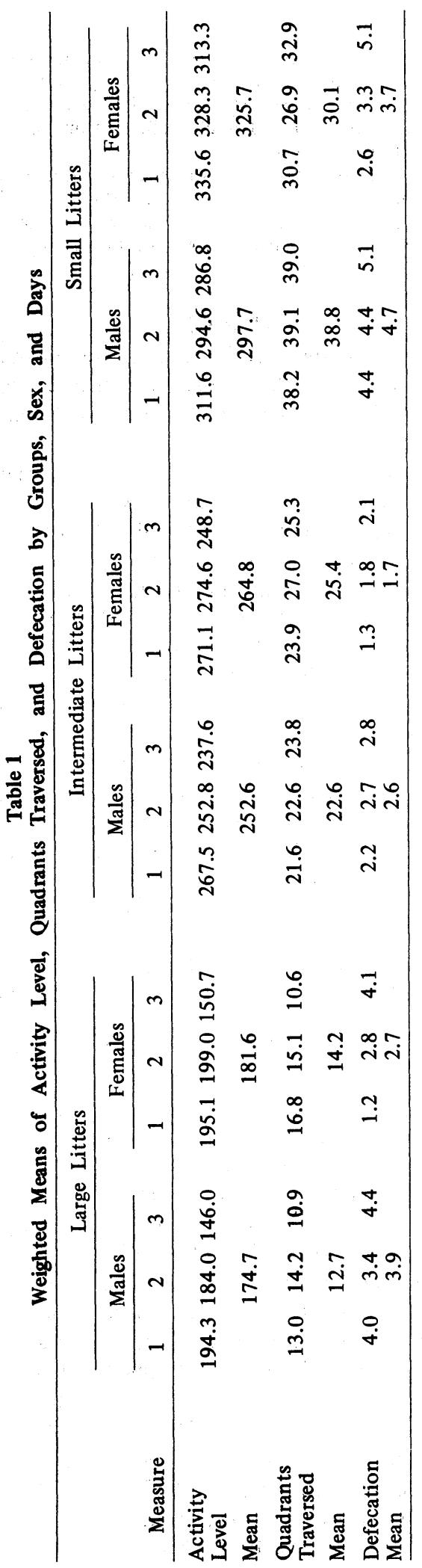

\section{DISCUSSION}

The results obtained in this study are consistent with those reported earlier (LaBarba \& White, 1971), with the exception of the defecation data. That is, the data strongly implicate litter size as one of the determinant variables in adult patterns of emotional reactivity in $B A L B / c$ mice. On the dependent measures of general activity level and quadrants traversed, large litters display higher levels of emotional reactivity than do smalland intermediate-sized litters, as these indices are typically interpreted. Quadrants traversed shows a linear function of decreased emotional reactivity with decreases in litter size. On the measure of activity level, the difference between the smalland intermediate-size litters was not significant, but small litters tended to be more active than intermediate litters, so that the direction was consistent. The defecation data with mice continues to be puzzling. Evidence that defecation in mice is a reliable and valid index of emotional reactivity has been inconsistent and controversial (LaBarba, Lutz, \& White, 1968; LaBarba \& Hodge, 1970). Collins (1966), for example, has suggested that defecation may not solely be an index of emotionality. Similarly, Bruell (1963) has argued that defecation in mice is a territorial response and not an emotional one. The point is that studies involving mice have produced equivocal results with the criterion measure of defecation as an emotionality index and that the unreliability of this index is in sharp contrast with other behavioral indices, such as activity level and quadrants traversed. The defecation data notwithstanding, the results of this study strengthen the notion that adult patterns of emotional reactivity in mice may differ as a function of variations in the litter size in which the organism was reared and that future studies in this area of investigation must control for litter size variations in order to avoid serious confounding of any data on emotional reactivity.

It is difficult to comment on the theoretical considerations underlying the phenomenon observed in this and earlier studies in the absence of more definitive data. It would appear, however, that a theory of infantile stimulation (Denenberg, 1964) most easily fits the data. The direction, source, quantitative, and qualitative aspects of stimulation input to infant organisms remain unanswered at this time. The development of new apparatus, such as the selective activity meter for use with rodents (Columbus Instruments), presents an exciting opportunity to obtain the data required for further analysis and understanding of the early infant stimulation model at this phylogenetic level.

\section{REFERENCES}

Bruell, J. H. Emotional defecation in mice: A territorial marking response? Paper presented at the annual meeting of the American Psychological Association, New York, 1963.

Collins, R. L. What else does the defecation score measure? Paper presented at the annual meeting of the American Psychological Association, New York, 1966.

Denenberg, V. H. Critical periods, stimulus input, and emotional reactivity: A theory of infantile stimulation. Psychological Bulletin, 1964, 71, 335-351.

LaBarba, R. C., Lutz, R., \& White, J. L. Partial maternal separation and adult emotionality in BALB/c mice. Psychonomic Science, 1968, 12, 301-302.

LaBarba, R. C., \& Hodge, R. Severe maternal separation and adult emotional reactivity in BALB/c mice. Psychonomic Science, 1970, 19, 154-155.

LaBarba, R. C., \& White, J. L. Litter size variations and emotional reactivity in BALB/c mice. Journal of Comparative \& Physiological Psychology, 1971, 75, 254-257.

(Received for publication September 18, 1972.) 